\title{
Neuroimaging in eating disorders
}

This article was published in the following Dove Press journal:

Neuropsychiatric Disease and Treatment

28 September 2011

Number of times this article has been viewed

\section{Ignacio Jáuregui-Lobera}

Behavioral Sciences Institute and Pablo de Olavide University, Seville, Spain
Correspondence: Ignacio Jáuregui-Lobera Virgen del Monte 3I, Seville 4I0I I, Spain Tel +3495428 0789

Fax +34954278167

Email ignacio-ja@telefonica.net

\begin{abstract}
Neuroimaging techniques have been useful tools for accurate investigation of brain structure and function in eating disorders. Computed tomography, magnetic resonance imaging, positron emission tomography, single photon emission computed tomography, magnetic resonance spectroscopy, and voxel-based morphometry have been the most relevant technologies in this regard. The purpose of this review is to update the existing data on neuroimaging in eating disorders. The main brain changes seem to be reversible to some extent after adequate weight restoration. Brain changes in bulimia nervosa seem to be less pronounced than in anorexia nervosa and are mainly due to chronic dietary restrictions. Different subtypes of eating disorders might be correlated with specific brain functional changes. Moreover, anorectic patients who binge/purge may have different functional brain changes compared with those who do not binge/ purge. Functional changes in the brain might have prognostic value, and different changes with respect to the binding potential of $5-\mathrm{HT}_{1 \mathrm{~A}}, 5-\mathrm{HT}_{2 \mathrm{~A}}$, and $\mathrm{D}_{2} / \mathrm{D}_{3}$ receptors may be persistent after recovering from an eating disorder.
\end{abstract}

Keywords: neuroimaging, brain changes, brain receptors, anorexia nervosa, bulimia nervosa, eating disorders

\section{Introduction}

Neuroimaging techniques have been useful tools for accurate investigation of brain structure and function in eating disorders, mainly in anorexia nervosa. ${ }^{1}$ The first studies, by means of structural neuroimaging, ie, computed tomography (CT) and magnetic resonance imaging (MRI), focused on the brain anatomy in patients with anorexia nervosa and consistently showed sulcal widening and ventricular enlargement that usually decreased with refeeding. ${ }^{2,3}$ Other specific findings have been a reduction in total gray and white matter volumes compared with healthy controls or the persistence of the gray matter volume changes when weight is restored. ${ }^{4,5}$ Some of these findings suggest that the changes are most likely to be due to neuronal damage secondary to malnutrition, with possible regeneration of myelin accounting for the general reversibility. ${ }^{4}$ However, these findings have not improved our understanding of the pathogenesis of anorexia nervosa. ${ }^{1}$ More recently, studies have highlighted the use of functional neuroimaging, which refers to techniques that obtain images of the brain according to its physiology and biochemistry. This technique provides information on the dynamics of the neural machinery involved in cognitive systems and emotional states, ${ }^{6}$ and thus offers far more information than does structural imaging. Functional neuroimaging studies have utilized positron emission tomography (PET) and single photon emission computed tomography (SPECT), the latter used mainly in studies of regional cerebral blood 
flow (rCBF). ${ }^{7}$ Other studies have used magnetic resonance spectroscopy $^{8}$ or voxel-based morphometry. ${ }^{9}$ With respect to PET and SPECT, studies can use fluoro-deoxy-glucose to analyze glucose metabolism or ligands specific for the serotonin receptor. Thus, these studies provide information for a neural system (eg, the $5 \mathrm{HT}_{2 \mathrm{~A}}$ receptor). The purpose of this review is to update the existing data on the main findings with respect to neuroimaging in eating disorders by means of a search conducted in PubMed.

\section{Early-onset anorexia nervosa}

The first study of early-onset anorexia nervosa, by means of SPECT, ${ }^{10}$ reported unilateral hypoperfusion in $87 \%$ of patients (children and adolescents aged 8-15 years), in which unilateral hypoperfusion was found on the left in eight of 13 patients, and on the right in five of 13 patients. In that study, the temporal lobe was hypoperfused in all cases. Years later, following the same line of research, ${ }^{7}$ SPECT findings showed that $73 \%$ of children and adolescents with anorexia nervosa had asymmetry (hypoperfusion) of blood flow in at least one area (temporal lobe, 9/15; parietal lobe, 5/15; frontal lobe, 3/15; thalamus, 3/15; and caudate nuclei, 1/15) of the brain. Considering the relationship between $\mathrm{rCBF}$ and several relevant variables (eg, cerebral dominance, nutritional status, length of illness, mood, eating disorder psychopathology, and cognitive profile), another study ${ }^{1}$ found that, in addition to unilateral reduction of blood flow in the temporal lobe and/or associated areas, approximately $75 \%$ of patients with early-onset anorexia nervosa showed no association between that reduction and cerebral dominance, nutritional status, length of illness, mood, or eating psychopathology. Nevertheless, there was a significant association between the abovementioned reduction and impaired visuospatial ability, impaired complex visual memory, and enhanced information processing.

In another study, conducted by Rastam et $\mathrm{al}^{11}$ in anorectic patients (mean age 22 years), seven years after onset of the illness, 66\% showed reduced blood flow in the temporal or associated regions, without a significant correlation between the reduction and body mass index, the lowest body mass index, residual eating disorder psychopathology, or intelligence quotient.

In a sample of adolescents with restrictive-type anorexia nervosa, in the early stages of the illness, morphometric gray matter changes were characterized by means of preprocessed MRI according to optimized voxel-based morphometry. The analyses revealed a significant decrease in global gray matter, and a significant region-specific decrease in gray matter volume was found bilaterally in the middle cingulate cortex, the precuneus, and the inferior and superior parietal lobules. $^{12}$

In general, the majority of the studies on anorexia nervosa have reported brain volume deficits and increased cerebrospinal fluid, suggesting starvation of the brain. ${ }^{4,13-18}$ In this regard, another study reported that right dorsal anterior cingulate cortex volume was significantly reduced in active patients with anorexia nervosa versus controls, and was correlated with lower performance intelligence quotients. ${ }^{19}$

\section{Brain changes in anorexia nervosa and weight restoration}

There is some debate about the abnormalities of cerebral blood flow in anorexia nervosa as to whether these abnormalities are secondary to starvation or indicative of a primary abnormality predating the illness, representing an underlying biological substrate. In a recent study, changes in $\mathrm{rCBF}$ were found at both baseline and follow-up (at more than 4 years). The main affected cerebral area was the medial temporal region, the data suggesting that $\mathrm{rCBF}$ does not return to normal following weight restoration. ${ }^{20}$

A previous study ${ }^{21}$ in female anorectic children (mean age 13.2 years), in which SPECT was performed at the beginning of treatment and after weight gain, reported relatively increased $\mathrm{rCBF}$ in the bilateral parietal and limbic lobes, including the posterior cingulate cortex, after weight gain. There was no significant decrease in the $\mathrm{rCBF}$ after weight gain. On the other hand, a significant positive correlation was observed between body mass index and $\mathrm{rCBF}$ in the right thalamus, right parietal lobe, and right cerebellum. These results were said to suggest that weight gain during the process of recovery from early-onset anorexia nervosa might activate specific brain regions that are possibly relevant to the pathophysiological aspects of the disorder.

In a pioneer study by Gordon et al, ${ }^{10}$ temporal lobe hypoperfusion persisted in three of four patients who had regained their normal weight. Furthermore, although two of the four patients had recovered a normal weight/height ratio after refeeding, the cognitive distortions of anorexia nervosa persisted, as well as the abnormal rCBF. This suggests that the hypoperfusion is not related directly to weight loss.

Another study using voxel-based morphometry showed that several temporal and parietal gray matter regions were reduced. During follow-up, there was a greater global increase in gray matter in anorectic patients, and this increase correlated with a decrease in cortisol. At follow-up (7 months), there were no differences in global gray matter 
and white matter volumes between anorectic patients and controls. The authors concluded that, in adolescent anorectic patients, gray matter is more affected than white matter and mainly involves the posterior regions of the brain. Overall, gray matter alterations are reversible after nutritional recovery. ${ }^{22}$ With regards to adult patients with anorexia nervosa, a decrease in cerebrospinal fluid and an increase in brain matter, as well as a reversal of ventricular enlargement, have been observed after weight restoration. ${ }^{13,16,17}$

The majority of the studies have been developed taking into account samples of adolescents and adults with restrictive-type anorexia nervosa. Considering the fact that it may be possible to find differences between patients at normal weight, patients after weight restoration, and controls, a recent study showed that patients with anorexia nervosa had a significant increase in gray and white matter volume after weight restoration. In addition, this study showed that patients had lower levels of gray matter at low weight compared with controls, which increased with weight restoration. ${ }^{23}$

Despite some differences, it seems that gray matter and white matter increase significantly following weight restoration. With respect to possible differences between adolescents and adults, it has been stated that gray matter is more affected than white matter in adolescents. ${ }^{22}$ The interaction among low weight, duration of illness, and brain changes remains controversial to some extent. Thus, while some authors have reported an inverse correlation between duration of illness and lower volume of gray matter at low body weight, but no correlation between low body weight and measures of brain volume, other authors have found a correlation between body mass index and brain volume, but not with duration of illness. ${ }^{18,23}$ Studying patients with anorexia nervosa who had a different duration of illness, Boghi et $\mathrm{al}^{24}$ found a significant reduction in total white matter volume and focal gray matter atrophy in the cerebellum, hypothalamus, caudate nucleus, and frontal, parietal, and temporal areas. The cerebellum was more affected in patients with a longer disease duration, whereas the hypothalamic alterations were more pronounced in patients with a shorter period of food restriction. A correlation between body mass index and gray matter was found in the hypothalamus. These authors suggested that atrophy of cerebellar gray matter could play a role in the chronic phase of the disease.

Frank et $\mathrm{al}^{25}$ studied groups of women with recovered restricting-type anorexia nervosa, recovered anorexia nervosa with a binging history, recovered bulimia nervosa without a history of anorexia nervosa, and controls, by means of PET and $\left[{ }^{15} \mathrm{O}\right]$ water in order to assess rCBF. Partial volume-corrected rCBF values in cortical and subcortical brain regions were similar between the groups. Neither current body mass index nor age correlated with $\mathrm{rCBF}$ values. The authors concluded that rCBF normalizes with long-term recovery, and stated that altered $\mathrm{rCBF}$ is unlikely to confound functional imaging studies in anorexia nervosa or bulimia nervosa after recovery. McCormick et $\mathrm{al}^{19}$ found that while anterior cingulate cortex normalization occurred with weight restoration, a smaller change in right dorsal anterior cingulate cortex volume prospectively predicted relapse after treatment. Another study using functional MRI reported that recovered patients with anorexia nervosa showed altered task-related activation in the medial prefrontal cortex, a critical node of the inhibitory control network. Specifically, whereas recovered patients with anorexia nervosa and control women showed similar medial prefrontal cortex activity during trials when inhibitory demand was low (ie, easy trials), recovered patients with anorexia nervosa showed significantly less medial prefrontal cortex activation than control women as inhibition trials became more difficult (ie, hard trials), suggesting a demand-specific modulation of inhibitory control circuitry in recovered patients with anorexia nervosa. ${ }^{26}$

\section{Brain changes in bulimia nervosa}

Structural brain changes on CT reported in cases of bulimia nervosa are similar to those described for anorexia nervosa, but less pronounced, and they have been related to chronic dietary restriction. ${ }^{27}$ Fewer studies of bulimia nervosa have been performed with MRI than for anorexia nervosa, and they have usually reported a decreased cortical mass. ${ }^{28-30}$

\section{Eating disorders and correlation with brain dysfunction}

The neural bases of eating disorders have been explored by means of neuroimaging studies employing different stimuli, such as food or body image. Functional MRI studies have reported that when malnourished patients with anorexia nervosa are shown pictures of food, they display abnormal activity in the insula and orbitofrontal cortex, as well as in other regions, like the mesial temporal and parietal regions, and anterior cingulate cortex. ${ }^{31-36}$ Using PET, SPECT, and functional MRI, patients with anorexia nervosa eating food or being exposed to food show activation of the temporal regions. ${ }^{31,33-36}$

Comparing chronic anorectic patients, recovered anorectic patients, and controls, Uher et $\mathrm{al}^{37}$ found increased medial prefrontal and anterior cingulate activation in response to food stimuli, as well as a lack of activity in the 
inferior parietal lobule, differentiating the recovered group from the healthy control subjects. Increased activation of the right lateral prefrontal, apical prefrontal, and dorsal anterior cingulate cortices differentiated recovered subjects from chronically ill patients. Group differences were specific to food stimuli, whereas processing of emotional stimuli did not differ between the groups. The authors concluded that separate neural correlates underlie trait and state characteristics of anorexia nervosa. The medial prefrontal response to disease-specific stimuli may be related to trait vulnerability. Lateral and apical prefrontal involvement is associated with a good outcome.

Functional MRI studies in women with full or subthreshold bulimia nervosa have reported less activation than healthy controls in the right anterior insula in response to anticipated receipt of a chocolate milkshake (versus tasteless solution) and in the left middle frontal gyrus, right posterior insula, right precentral gyrus, and right mid dorsal insula in response to consumption of a milkshake (versus tasteless solution). ${ }^{38}$

Other studies have sought brain correlates for severe body image distortion. Boghi et $\mathrm{al}^{24}$ have suggested that involvement of the temporoparietal areas in brain atrophy could account for body image distortion. High responsiveness in the frontal visual system of the brain and the attention network, as well as the inferior parietal lobe, including the anterior part of the intraparietal sulcus, has been described in patients with anorexia nervosa when confronted with their own digitally distorted body image as well as an image of a different person. Moreover, patients with anorexia nervosa were reported to show only an increase in activation in response to their own pictures and not to those of others, indicating different visuospatial processing, while controls did not differentiate. ${ }^{39}$ In another study, PET showed a negative relationship between $5 \mathrm{HT}_{2 \mathrm{~A}}$ receptor activity in the left parietal cortex, right occipital cortex, and left subgenual cingulate and the subscale of drive for thinness on the Eating Disorders Inventory. ${ }^{40}$ It is well known that the parietal cortex mediates perceptions of the body, and disturbances in the left hemisphere may contribute to body image distortion.

Different components of body image (satisfaction rating and size estimation) have been studied in patients with anorexia nervosa using functional MRI. Anorectic patients were less satisfied with their current body shape than controls. Patients showed stronger activation of the insula and lateral prefrontal cortex during the satisfaction rating of thin self-image, indicating a stronger emotional involvement when presented with distorted images close to their own ideal body size. In addition, patients overestimated their own body size. ${ }^{41}$

Brain involvement in body image satisfaction has been studied, not only in patients but also in healthy people without an eating disorder. In a sample of healthy young women, the impact of images of slim female fashion models was analyzed by functional neuroimaging. The level of reported anxiety during exposure to slim bodies correlated with established measures of shape and weight concern and brain activation in the bilateral basal ganglia, left amygdala, bilateral dorsal anterior cingulate, and left inferior lateral prefrontal cortex. ${ }^{42}$

Similar studies have highlighted the relevance of analysis of the correlation between body image therapy and activation of brain regions involved in body image representation. Vocks et $\mathrm{al}^{43}$ analyzed neuronal responses to viewing photographs of one's own body before and after treatment in patients with anorexia nervosa by MRI. Decreases in activation emerged in a distributed network, and increases were observed in the extrastriate body area, possibly reflecting more intense body image processing.

\section{Different types of eating disorders}

A controlled near-infrared spectroscopy study was developed to identify brain correlates with different types of eating disorders. Regional hemodynamic changes in the bilateral orbitofrontal and right frontotemporal regions were significantly smaller in the eating disorder group than in the control group, and negatively correlated with dieting tendency scores in the Eating Attitudes Test-26 in the right frontotemporal regions, and correlated with eating restriction and binge eating scores in the left orbitofrontal regions. In conclusion, the authors stated that the tendency towards dieting correlates with the right frontotemporal cortex, and that dieting behavior problems correlate with the left orbitofrontal cortex. ${ }^{44}$

In addition to investigations for brain correlations with different eating disorder symptoms, other studies have tried to explore possible and specific brain correlations with different subtypes of eating disorder. Using SPECT, Beato-Fernández et $\mathrm{al}^{45}$ found that patients with anorexia nervosa showed hyperactivation of the left parietal and right superior frontal areas in response to a positive video stimulus (the patient's filmed body image) compared with a neutral (landscape) stimulus, whereas patients with bulimia nervosa showed hyperactivation of the right temporal and right occipital areas. The authors concluded that functional brain abnormalities in patients with anorexia nervosa might be related to storage of a distorted prototypic image of the body in the left parietal lobe, and the activation of the right temporal area after 
exposure to images of their own body might be consistent with the adverse response. Following this study, the same researchers ${ }^{46}$ used SPECT to investigate the discriminatory capacity of these psychopathological and neurobiological variables with regards to different eating disorders. Patients with nonpurging-type bulimia nervosa showed less eating and general psychopathology. Furthermore, unlike patients with restrictive-type anorexia nervosa and purging-type bulimia nervosa, they did not demonstrate an increase in rCBF when confronted with their own body image. Temporal right hyperactivation was one of the discriminatory variables tested. In this study, the authors concluded that the subgroup with nonpurging-type bulimia nervosa showed less emotional alteration and less emotional response when shown their own body image than the patients with other eating disorders.

Another study ${ }^{34}$ analyzed the effect of imagining food on rCBF in patients with anorexia nervosa with and without binge/ purging behavior. The patients with anorexia nervosa accompanied by habitual binge/purge behavior showed a significantly higher percent change in the inferior, superior, prefrontal, and parietal regions of the right brain than healthy volunteers and patients with restrictive-type anorexia nervosa. The patients with habitual binge/purge behavior also had the highest level of apprehension concerning food intake. Using SPECT, Karhunen et $\mathrm{al}^{47}$ found similarly high $\mathrm{rCBF}$ in the right parietal and temporal cortical areas in obese women looking at food than in normal weight women looking at food. Recognition of the parietal cortex as a mediator of body image perceptions has led to the suggestion that the parietal lobe contributes to the awareness of being responsible for one's own actions. ${ }^{48}$

\section{Brain changes and clinical outcomes}

Comparing the results of basal SPECT and clinical outcome in patients with eating disorders, it has been found that temporal hypoperfusion in the acute phase is correlated with the long-term clinical outcome, suggesting a prognostic value of temporal hypoperfusion. ${ }^{49}$ This finding confirms the results of another study developed by the same research team in which hypoperfusion of the anterior inferior region of the temporal lobe, predominantly in the left hemisphere, was found in the acute phase of the illness. ${ }^{50}$ Some brain changes, found among different subtypes of eating disorder, have been suggested to be possible prognostic factors. ${ }^{46}$

\section{Neuroimaging and neurotransmitters}

Brain imaging using PET and development of selective tracers for the 5-HT system have enabled in vivo analysis of
5-HT receptor function. With respect to the $5-\mathrm{HT}_{1 \mathrm{~A}}$ receptor, anorectic patients showed a marked increase $(30 \%-70 \%)$ in $\left[{ }^{11} \mathrm{C}\right]$ WAY-100635BP, a selective ligand in the prefrontal and lateral orbital frontal regions, mesial and lateral temporal lobes, parietal cortex, and dorsal raphe nuclei. ${ }^{51} \mathrm{PET}$ and $\left[{ }^{11} \mathrm{C}\right]$ WAY-100635 studies showed that binding potential values in all brain regions investigated were greater in patients with bulimia nervosa than in control subjects. The most robust differences were observed at the angular gyrus, the medial prefrontal cortex, and the posterior cingulate cortex. The authors suggested that brain $5-\mathrm{HT}_{1 \mathrm{~A}}$ receptor binding is increased in several cortical areas in patients with bulimia nervosa during bouts of impulsive binge eating. ${ }^{52}$

With respect to $5-\mathrm{HT}_{2 \mathrm{~A}}$ receptors, it has been found using PET that anorectic patients had normal values of the $\left[{ }^{18} \mathrm{~F}\right]$ altanserin radioligand. ${ }^{51}$ Using SPECT and ${ }^{123}$ I-5-I-R91150, a significantly reduced $5-\mathrm{HT}_{2 \mathrm{~A}}$ binding index was shown in the left frontal cortex, left and right parietal cortex, and left and right occipital cortex in patients with anorexia nervosa compared with healthy volunteers. A significant left-right asymmetry was noted in the frontal cortex (left less than right). ${ }^{53}$

\section{Neuroimaging, neurotransmitters, and recovery}

Bailer et $\mathrm{al}^{54}$ studied different subtypes of eating disorder after recovery (normal body weight maintained for more than one year, regular menstrual cycles, no binging or purging) using PET and $\left[{ }^{11} \mathrm{C}\right] \mathrm{McN} 5652$. They found that both controls and patients with restrictive anorexia nervosa, purging anorexia nervosa, and bulimia nervosa showed significant differences in $\left[{ }^{11} \mathrm{C}\right] \mathrm{McN} 5652 \mathrm{BP}$ values in the dorsal raphe and anteroventral striatum. Post hoc analysis revealed that patients with recovered restrictive anorexia nervosa had significantly increased $\left[{ }^{11} \mathrm{C}\right] \mathrm{McN} 5652 \mathrm{BP}$ compared with those having recovered purging anorexia nervosa in these regions. With respect to bulimia nervosa, Bailer et $\mathrm{al}^{55}$ used PET and $\left[{ }^{11} \mathrm{C}\right]$ WAY100635 to investigate a sample of recovered bulimic patients and found that they had a 23\%-34\% elevation of $\left[{ }^{11} \mathrm{C}\right]$ WAY binding potential in the subgenual cingulate, mesial temporal, and parietal regions, and confirmed these results using 5-HT transporter measures. Pichika et $\mathrm{al}^{56}$ found that recovered bulimic patients had significantly lower $\left[{ }^{11} \mathrm{C}\right]$ DASB binding potential (nondisplaceable) in the midbrain and superior and inferior cingulate, as well as a significantly higher $\left[{ }^{11} \mathrm{C}\right]$ DASB binding potential (nondisplaceable) in the anterior cingulate and superior temporal gyrus on voxel-based analysis. Region of interest analysis indicated 
a lower $\left[{ }^{11} \mathrm{C}\right]$ DASB binding potential (nondisplaceable) in the midbrain, including in the dorsal raphe, in patients with recovered bulimia nervosa, consistent with earlier studies.

Individuals with recovered restrictive anorexia nervosa have shown a reduced $\left[{ }^{18} \mathrm{~F}\right]$ altanserin binding potential in the mesial temporal and parietal cortical areas, as well as in the subgenual and pregenual cingulate cortex. ${ }^{57}$ Similarly, women with recovered purging anorexia nervosa have shown a reduced $\left[{ }^{18} \mathrm{~F}\right]$ altanserin binding potential relative to controls in the left subgenual cingulate, left parietal, and right occipital cortex.$^{58}$ Further, women with recovered bulimia nervosa have shown a reduced $\left[{ }^{18} \mathrm{~F}\right]$ altanserin binding potential relative to controls in the orbital frontal region. In summary, it is suggested that the altered 5- $\mathrm{HT}_{1 \mathrm{~A}}$ and 5- $\mathrm{HT}_{2 \mathrm{~A}}$ receptor binding potential in recovered patients is reflected in persistent alterations in the frontal, subgenual cingulate, and mesial temporal regions that are part of the ventral limbic system. ${ }^{48}$

In a PET investigation of dopamine $\mathrm{D}_{2} / \mathrm{D}_{3}$ receptor binding in recovered patients, using PET with $\left[{ }^{11} \mathrm{C}\right]$ raclopride, Frank et $\mathrm{al}^{59}$ found that women who were recovered from anorexia nervosa had a significantly higher $\left[{ }^{11} \mathrm{C}\right]$ raclopride binding potential in the anteroventral striatum than controls. The $\left[{ }^{11} \mathrm{C}\right]$ raclopride binding potential was positively correlated with harm avoidance in the dorsal caudate and dorsal putamen in subjects with recovered anorexia nervosa.

PET imaging studies in both ill patients and those with a recovered eating disorder have found significant correlations between harm avoidance and $5-\mathrm{HT}_{1 \mathrm{~A}}, 5-\mathrm{HT}_{2 \mathrm{~A}}, \mathrm{DA} \mathrm{D}_{2} / \mathrm{D}_{3}$ receptor binding in the mesial temporal and other limbic regions ${ }^{48}$ It has been suggested that premorbid onset and the persistence of anxiety and harm avoidance symptoms after recovery are traits that contribute to the pathogenesis of anorexia nervosa and bulimia nervosa. The PET imaging data suggest that such behaviors are related to disturbances of 5-HT and dopamine neurotransmitter function in the limbic and executive pathways. ${ }^{48}$

\section{Discussion}

It must be noted that neuroimaging studies in eating disorders have varied widely in terms of sample size, imaging technology used, age of participants, brain regions assessed, and duration of illness. Sample sizes have usually been small, which potentially affects the statistical power of these studies. To date, the main limitation of this type of research is that the studies have not consistently identified brain regions, pathways, or clear behavioral correlates. As has been noted, ${ }^{48}$ functional neuroimaging studies in mixed populations (children, adolescents, and adults) have yielded inconsistent results due to the wide age range, use of different equipment, the different interpretation methods used, failure to control for emotional arousal, comorbidity, whether imaging was done before or after a meal, and a number of other methodological problems. In addition, the actual neuroimaging techniques may produce varying results, because each technique measures something slightly different. ${ }^{7}$ Also, different results can be obtained depending on the isotope used, the type of camera, the scanning parameters, and the method of data analysis. ${ }^{60}$

With respect to the neurocircuitry involved in the psychopathology of eating disorders, it is worth mentioning that the brain is neither an undifferentiated whole nor a collection of parts or areas ${ }^{61}{ }^{1}$ In this regard, its overall function is the result of a complex interaction between different brain areas and their interconnections. Following this principle, an eating disorder might emerge as a consequence of disturbance of a system of interconnecting pathways or circuits in the brain which regulate cognition, emotion, appetite, and visual perception. $^{7}$

In the future, neuroimaging might become a useful tool for follow-up of the recovery process, enabling clinicians to differentiate between patients who are recovering successfully and those who remain chronically ill. Among these future trends, the study of brain correlates with body image dissatisfaction as well as body image distortion might be useful from a diagnostic point of view and, moreover, serve as a tool to confirm the efficacy of treatment focused on body image disturbance. The study of clinical subtypes of eating disorders, usually based on the presence or absence of binge/purging behavior, is another area of research in which neuroimaging might contribute to our knowledge about different types of eating disorders from a biological perspective. In addition, use of functional neuroimaging in the search for specific neurotransmitter imbalances in the brain could contribute to improved use of current medications widely used in eating disorders.

\section{Conclusion}

In general, studies of anorexia nervosa have reported brain volume deficits and increased cerebrospinal fluid, indicating the effects of starvation in the brain. Despite some controversial results, it appears that the gray and white matter increase significantly following weight restoration. Brain changes in bulimia nervosa seem to be less pronounced and are mainly due to chronic dietary restriction. In response to different food stimuli, patients with anorexia nervosa show activation 
in the temporal regions, and patients with bulimia nervosa show less activation than healthy controls in the right anterior insula, left middle frontal gyrus, right posterior insula, right precentral gyrus, and right mid dorsal insula. Body image distortion has been used to look for correlations between eating disorders and changes in the brain. Involvement of the temporoparietal areas with respect to brain atrophy might account for body image disturbances. A tendency towards dieting seems to correlate with the right frontotemporal cortex, and dieting behavior seems to correlate with the left orbitofrontal cortex.

A number of studies have attempted to identify specific brain correlates, taking into account the subtypes of eating disorders. Patients with anorexia nervosa have shown hyperactivation of the left parietal and right superior frontal areas in response to a neutral or positive stimulus, whereas patients with bulimia nervosa have shown hyperactivation of the right temporal and right occipital areas. Moreover, unlike patients with restrictive anorexia nervosa and purging bulimia nervosa, patients with nonpurging bulimia nervosa do not experience increased $\mathrm{rCBF}$ when confronted with their own body image. Considering the difference between patients with anorexia nervosa with and without binge/purging behavior, it has been reported that patients with anorexia nervosa with habitual binge/purge behavior have a significantly higher percent change in the inferior, superior, prefrontal, and parietal regions of the right brain. The outcome of an eating disorder has been related to certain brain changes, suggesting that temporal hypoperfusion may have a prognostic value. Changes in $5-\mathrm{HT}_{1 \mathrm{~A}}$ and $5-\mathrm{HT}_{2 \mathrm{~A}}$ receptor binding potential may be persistent after recovery from an eating disorder. The same applies to some changes in $\mathrm{D}_{2} / \mathrm{D}_{3}$ receptor binding.

\section{Disclosure}

The author reports no conflicts of interest in this work.

\section{References}

1. Lask B, Gordon I, Christie D, Frampton I, Chowdhury U, Watkins B. Functional neuroimaging in early-onset anorexia nervosa. Int $J$ Eat Disord. 2005;37 Suppl:S49-S51.

2. Palazidou E, Robinson P, Lishman WA. Neuroradiological and neuropsychological assessment in anorexia nervosa. Psychol Med. 1990; 20(3):521-527.

3. Katzmann DK, Zipursky RB, Lambe EK, Mikulis D. A longitudinal magnetic resonance imaging study of brain changes in adolescents with anorexia nervosa. Arch Pediatr Adolesc Med. 1997;151(8):793-797.

4. Artmann H, Grau H, Adelmann T, Schleiffer R. Reversible and nonreversible enlargement of cerebrospinal fluid space in anorexia nervosa. Neuroradiology. 1985;27(4):304-312.

5. Krieg JC, Pirke KM, Lauer C, Backmund H. Endocrine, metabolic, and cranial computed tomographic findings in anorexia nervosa. Biol Psychiatry. 1988;23(4):377-387.
6. Coyle J. Foreword. In: Ernst M, Rumsey J, editors. Functional Neuroimaging in Child Psychiatry. Cambridge, MA: Cambridge University Press; 2000:13.

7. Chowdhury U, Gordon I, Lask B, Watkins B, Watt H, Christie D. Early-onset anorexia nervosa: is there evidence of limbic system imbalance? Int J Eat Disord. 2003;33(4):388-396.

8. Rost B, Roser W, Bubl R, Radue EW, Buergin D. MRS of the brain in patients with anorexia or bulimia nervosa. Hosp Med. 1999;60(7):474-476.

9. Mühlau M, Gaser C, Ilg R, et al. Gray matter decrease of the anterior cingulate cortex in anorexia nervosa. Am J Psychiatry. 2007;164(12):1850-1857.

10. Gordon I, Lask B, Bryant-Waugh R, Christie D, Timimi S. Childhoodonset anorexia nervosa: towards identifying a biological substrate. Int J Eat Disord. 1997;22(2):159-165.

11. Rastam M, Bjure J, Vestegren E, et al. Regional cerebral blood flow in weight-restored anorexia nervosa: a preliminary study. Dev Med Child Neurol. 2001;43(4):239-242.

12. Gaudio S, Nocchi F, Franchin T, et al. Gray matter decrease distribution in the early stages of Anorexia Nervosa restrictive type in adolescents. Psychiatry Res. 2011;191(1):24-30.

13. Dolan RJ, Mitchell J, Wakeling A. Structural brain changes in patients with anorexia nervosa. Psychol Med. 1988;18(2):349-353.

14. Golden NH, Ashtari M, Kohn MR, et al. Reversibility of cerebral ventricular enlargement in anorexia nervosa, demonstrated by quantitative magnetic resonance imaging. J Pediatr. 1996;128(2):296-301.

15. Swayze VW, Andersen A, Arndt S, et al. Reversibility of brain tissue loss in anorexia nervosa assessed with a computerized Talairach 3-D proportional grid. Psychol Med. 1996;26(2):381-390.

16. Kohlmeyer K, Lehmkuhl G, Poustka F. Computed tomography of anorexia nervosa. AJNR Am J Neuroradiol. 1983;4(3):437-438.

17. Neumarker KJ, Bzufka WM, Dudeck U, Hein J, Neumarker U. Are there specific disabilities of number processing in adolescent patients with anorexia nervosa? Evidence from clinical and neuropsychological data when compared to morphometric measures from magnetic resonance imaging. Eur Child Adolesc Psychiatry. 2000;9 Suppl 2:II111-II121.

18. Katzman DK, Lambe EK, Mikulis DJ, Ridgley JN, Goldbloom DS, Zipursky RB. Cerebral gray matter and white matter volume deficits in adolescent girls with anorexia nervosa. J Pediatr 1996;129(6): 794-803.

19. McCormick LM, Ziebell S, Nopoulos P, Cassell M, Andreasen NC, Brumm M. Anterior cingulate cortex: an MRI-based parcellation method. Neuroimage. 2006;32(3):1167-1175.

20. Frampton I, Watkins B, Gordon I, Lask B. Do abnormalities in regional cerebral blood flow in anorexia nervosa resolve after weight restoration? Eur Eat Disord Rev. 2011;19(1):55-58.

21. Komatsu H, Nagamitsu S, Ozono S, Yamashita Y, Ishibashi M, Matsuishi T. Regional cerebral blood flow changes in early-onset anorexia nervosa before and after weight gain. Brain Dev. 2010;32(8): 625-630.

22. Castro-Fornieles J, Caldú X, Andrés-Perpiñá S, et al. A cross-sectional and follow-up functional MRI study with a working memory task in adolescent anorexia nervosa. Neuropsychologia. 2010;48(14): 4111-4116.

23. Roberto CA, Mayer LE, Brickman AM, et al. Brain tissue volume changes following weight gain in adults with anorexia nervosa. Int $J$ Eat Disord. 2011;44(5):406-411.

24. Boghi A, Sterpone S, Sales S, et al. In vivo evidence of global and focal brain alterations in anorexia nervosa. Psychiatry Res. 2011;192(3): 154-159.

25. Frank GK, Bailer UF, Meltzer CC, et al. Regional cerebral blood flow after recovery from anorexia or bulimia nervosa. Int $J$ Eat Disord. 2007;40(6):488-492.

26. Oberndorfer TA, Kaye WH, Simmons AN, Stigo IA, Matthews SC. Demand-specific alteration of medial prefrontal cortex response during an inhibition task in recovered anorexic women. Int $J$ Eat Disord. 2011;44(1):1-8. 
27. Krieg JC, Lauer C, Pirke KM. Structural brain abnormalities in patients with bulimia nervosa. Psychiatry Res. 1989;27(1):39-48.

28. Laessle RG, Krieg JC, Fichter MM, Pirke KM. Cerebral atrophy and vigilance performance in patients with anorexia and bulimia nervosa. Neuropsychobiology. 1989;21(4):187-191.

29. Hoffman GW, Ellinwood EH Jr, Rockwell WJ, Herfkens RJ, Nishita JK, Guthrie LF. Cerebral atrophy in bulimia. Biol Psychiatry. 1989;25(7):894-902.

30. Husain MM, Black KJ, Doraiswamy PM, et al. Subcortical brain anatomy in anorexia and bulimia. Biol Psychiatry. 1992;31(7):735-738.

31. Nozoe S, Naruo T, Nakabeppu Y, Soejima Y, Nakajo M, Tanaka H. Changes in regional cerebral blood flow in patients with anorexia nervosa detected through single photon emission tomography imaging. Biol Psychiatry. 1993;34(8):578-580.

32. Nozoe S, Naruo T, Yonekura R, et al. Comparison of regional cerebral blood flow in patients with eating disorders. Brain Res Bull. 1995;36(3):251-255.

33. Ellison Z, Foong J, Howard R, Bullmore E, Williams S, Treasure J. Functional anatomy of calorie fear in anorexia nervosa. Lancet. 1998; 352(9135): 1192

34. Naruo T, Nakabeppu Y, Sagiyama K, et al. Characteristic regional cerebral blood flow patterns in anorexia nervosa patients with binge/ purge behavior. Am J Psychiatry. 2000;157(9):1520-1522.

35. Gordon CM, Dougherty DD, Fischman AJ, et al. Neural substrates of anorexia nervosa: a behavioral challenge study with positrón emission tomography. J Pediatr. 2001;139(1):51-57.

36. Uher R, Murphy T, Brammer M, et al. Medial prefrontal cortex activity associated with symptom provocation in eating disorders. Am J Psychiatry. 2004;161(7):1238-1246.

37. Uher R, Brammer MJ, Murphy T, et al. Recovery and chronicity in anorexia nervosa: brain activity associated with differential outcomes. Biol Psychiatry. 2003;54(9):934-942.

38. Bohon C, Stice E. Reward abnormalities among women with full and subthreshold bulimia nervosa: A functional magnetic resonance imaging study. Int J Eat Disord. 2010. [Epub ahead of print.]

39. Wagner A, Ruf M, Braus DF, Schmidt MH. Neuronal activity changes and body image distortion in anorexia nervosa. Neuro Report. 2003;14(17):2193-2197.

40. Bailer UF, Price JC, Meltzer CC, et al. Altered 5-HT(2A) receptor binding after recovery from bulimia-type anorexia nervosa: relationships to harm avoidance and drive for thinness. Neuropsychopharmacology. 2004;29(6):1143-1155.

41. Mohr HM, Zimmermann J, Röder C, Lenz C, Overbeck G, Grabhorn R. Separating two components of body image in anorexia nervosa using fMRI. Psychol Med. 2010;40(9):1519-1529.

42. Friederich HC, Uher R, Brooks S, et al. I'm not as slim as that girl: neural bases of body shape self-comparison to media images. Neuroimage. 2007;37(2):674-681.

43. Vocks S, Busch M, Schulte D, Grönermeyer D, Herpertz S, Suchan B. Effects of body image therapy on the activation of the extrastriate body area in anorexia nervosa: an fMRI study. Psychiatry Res. 2010;183(2): 114-118.

44. Suda M, Uehara T, Fukuda M, Sato T, Kameyama M, Mikuni M. Dieting tendency and eating behavior problems in eating disorder correlate with right frontotemporal and left orbitofrontal cortex: a near-infrared spectroscopy study. J Psychiatr Res. 2010;44(8):547-555.
45. Beato-Fernández L, Rodríguez-Cano T, García-Vilches, et al. Changes in regional cerebral blood flow after body image exposure in eating disorders. Psychiatry Res. 2009;171(2):129-137.

46. Beato-Fernández L, Rodríguez-Cano T, García-Vilches I. Psychopathological alterations and neuroimaging findings with discriminant value in eating behavior disorders. Actas Esp Psiquiatr. 2011;39(4):203-210.

47. Karhunen LJ, Lappalainen RI, Vanninen EJ, Kuikka JT, Uusitupa MI. Regional cerebral blood flow during food exposure in obese and normalweight women. Brain. 1997;120 (Pt 9):1675-1684.

48. Fox EA. Purdue Ingestive Behavior Research Center symposium 2007: influences on eating and body weight over the lifespan - childhood and adolescence. Physiol Behav. 2008;94(1):1-7.

49. Jiménez-Bonilla JF, Quirce R, Banzo I, et al. Temporal hypoperfusion assessed by cerebral blood flow SPECT and long-term clinical outcome in patients with eating disorders. Clin Nucl Med. 2009;34(11):768-772.

50. Jiménez-Bonilla JF, Carril Carril JM, Quirce Pisano R, et al. Assessment of cerebral blood flow in patients with eating disorders in the acute clinical phase using Tc99m-HMPAO spect. Rev Esp Med Nucl. 2008;27(5):350-354.

51. Bailer UF, Frank GK, Henry SE, et al. Exaggerated 5-HT1A but normal 5-HT2 A receptor activity in individuals ill with anorexia nervosa. Biol Psychiatry. 2007;61(9):1090-1099.

52. Tiihonen J, Keski-Rahkonen A, Löppönen M, et al. Brain serotonin 1A receptor binding in bulimia nervosa. Biol Psychiatry. 2004;55(8): 871-873.

53. Audenaert K, Van Laere K, Dumont F, et al. Decreased 5-HT2A receptor binding in patients with anorexia nervosa. $J$ Nucl Med. 2003;44(2):163-169.

54. Bailer UF, Frank GK, Henry SE, et al. Serotonin transporter binding after recovery from eating disorders. Psychopharmacology (Berl). 2007;195(3):315-324.

55. Bailer UF, Bloss CS, Frank GK, et al. 5-HT(1A) receptor binding is increased after recovery from bulimia nervosa compared to control women and is associated with behavioral inhibition in both groups. Int $J$ Eat Disord. 2011;44(6):477-487.

56. Pichika R, Buchsbaum MS, Bailer U, et al. Serotonin transporter binding after recovery from bulimia nervosa. Int J Eat Disord. 2011. [Epub ahead of print.]

57. Frank GK, Kaye WH, Meltzer CC, et al. Reduced 5-HT2A receptor binding after recovery from anorexia nervosa. Biol Psychiatry. 2002;52(9):896-906.

58. Bailer UF, Price JC, Meltzer CC, et al. Altered 5-HT(2A) receptor binding after recovery from bulimia-type anorexia nervosa: relationships to harm avoidance and drive for thinness. Neuropsychopharmacology. 2004;29(6):1143-1155.

59. Frank G, Bailer UF, Henry S, et al. Increased dopamine D2/D3 receptor binding after recovery from anorexia nervosa measured by positron emission tomography and $\left[{ }^{11} \mathrm{C}\right]$ raclopride. Biol Psychiatry. 2005;58(11):908-912.

60. Drevets W. Neuroimaging studies of major depression. In: Morisha J, editor. Advances in Brain Imaging. Washington, DC: American Psychiatric Publishing Inc; 2001.

61. Kalat J. Biological Psychology. 7th ed. Belmont, CA: Wadsworth; 2001.

\section{Dovepress}

\section{Publish your work in this journal}

Neuropsychiatric Disease and Treatment is an international, peerreviewed journal of clinical therapeutics and pharmacology focusing on concise rapid reporting of clinical or pre-clinical studies on a range of neuropsychiatric and neurological disorders. This journal is indexed on PubMed Central, the 'PsycINFO' database and CAS, and is the official

Submit your manuscript here: http://www.dovepress.com/neuropsychiatric-disease-and-treatment-journal journal of The International Neuropsychiatric Association (INA). The manuscript management system is completely online and includes a very quick and fair peer-review system, which is all easy to use. Visit $\mathrm{http} / / / \mathrm{www}$. dovepress.com/testimonials.php to read real quotes from published authors. 